\title{
MAPPING AND RANGING OF CULTURAL AND CREATIVE INDUSTRIES IN THE CITY OF PLOVDIV
}

\author{
Vesela Kazashka, ${ }^{1}$ Margarita Ruseva, ${ }^{2}$ Paulina Stoyanova ${ }^{3}$
}

\begin{abstract}
This paper reflects the goals and objectives of the fundamental scientific research project "Young Scientists 2016" at the Scientific Research Fund of the Bulgarian Ministry of Education and Science.

The aim of this research is to analyze and map the cultural industries in Plovdiv. The intention is the resources of cultural industries to be researched using empirical data and then based on this research to be ranged and mapped. Furthermore, the research team is looking for a new model and tool-set for appraisal of the cultural industries. The methods employed are based on success indicators borrowed from economics and statistics.
\end{abstract}

UDC Classification: 7.1/06; DOI: http://dx.doi.org/10.12955/cbup.v5.999

Keywords: cultural and creative industries; mapping, ranging, Plovdiv

\section{Introduction}

Cultural industries are a reflection of science, education, culture and the personal development of man and the nation. They exhibit historical, cultural, spiritual and religious processes in the community. Cultural industries are an actual sector of economy.

In the last 25 years Bulgaria has undergone a transition from a closed to a market economy. This fact has also influenced the development of the cultural industries in the country. An exchange of cultural and creative resources has been made possible. The representation of cultural industries has been changed, too. Following the accession of Bulgaria to EU, a trend towards stimulating our cultural and creative identity has been noted. The national culture of the EU member states is not only a local national priority of each country, but also of the EU, as seen in the European strategic documents (Barkalova, Kazashka, 2010).

\section{Scoping analyze - target arts}

The new opportunities have led to the elaboration and supply of many programs, politics and strategies relating to cultural industries.

Prof. Prodanov (2005) distinguishes four major community functions of culture: The first function is the unifying of the separate individuals into forming a common identity. The second function of culture is forming social capital and trust which facilitates the voluntary gathering of individuals in pursuit of common goals. The third function is legitimation of the authority structures. The fourth function of culture is rendering existential meaning for human life through creating a common horizon of existential acts in large groups of individuals. By means of these functions humans discover the unifying cultural identity that rationalizes their behavior both within and beyond their being. (Prodanov, 2005).

Plovdiv is the second largest city of Bulgaria, next to the capital city, and it is the oldest living city in Europe. It is situated on the banks of the Maritsa river, with green hills in its heart. It has been known, since ancient times, as the "The City of the Seven Hills," which defines part of its identity. Since the time of its founding in $6000 \mathrm{BC}$, it has been continuously inhabited, being a cultural and commercial center. The antique beauty of Plovdiv, its strategic location and the whole year-round cultural events determine it as a place of constant encounters of cultures and civilizations. Plovdiv is a combination of heritage and prospects. It is the heir of many civilizations and their culture, a mixture of unique resources, traditions and ancient and contemporary art.

There are five main rules that govern the urban economy. These are rules that economic entities should comprehend, accept and apply in their actions. They determine the functioning and development of five markets: (1) the commodities and services market; (2) the labor market; (3) the proprietary investments market; (4) the land market; (5) the urban economy public benefits market. From this

\footnotetext{
${ }^{1}$ Academy of Music, Dance and Fine Arts, cpo@artacademyplovdiv.com

${ }^{2}$ Plovdiv's University "Paisyi Hilendarsky“, ruseva_margarita@mail.bg

${ }^{3}$ Plovdiv's University "Paisyi Hilendarsky“, paulina_stoyanova@abv.bg
} 
perspective, the general urban economic development is a function of their dynamics (Urban Research, 2012). The development of cultural industries in urban centers is related to the development of the city itself, the market principles, the labor market, and the proprietary investments.

The resources that make Plovdiv a major cultural center and are a prerequisite for its being a European Capital of Culture in 2019 are as follows:

- Geographic facts - geographic location, landscape, climate, waters, eco-sphere, biosphere;

- Historical and cultural heritage - arts and architecture, living culture and intangible cultural heritage: folklore, crafts, traditions, cultural events;

- Population and personalities (contemporary and historical), inhabitants, cultural diversity;

- Infrastructure - transport infrastructure, tourist destination, halls, facilities, communications, services, banking, hospitality business;

- Economy - existence and implementation of projects, investments, cultural development strategies.

Prof. Ivan Chalakov (2006) has found that cultural industries in Plovdiv represent $10 \%$ of the functioning economic entities and account for about $4 \%$ of the net profit. Culture industries provide employment to 1 of 20 inhabitants. The employers are mainly micro-companies not exceeding 10 employees and sales volume of Euro 50 000. (Chalakov, 2006).

Studies prove that cultural industries are a dynamic sector with significant effect over the economy of Europe and Bulgaria, and in this particular case - the city of Plovdiv. This effect is a key mechanism and it is generated by the individual's need of the cultural industries. The impact of the operations of cultural industries is multidimensional and encompasses:

1) Economic effects demonstrated by employment among the population, making profit, promotion of innovation, and introduction of new technology;

2) Social effects, the result of which is the encouragement of creativity;

3) Cultural effects seen in fostering the cultural diversity, preserving the cultural and national identity, the satisfaction of those engaged in cultural industries.

The sources of funding for cultural industries are various, but, the major part is that of the government. On one side is the regulatory system conforming with the European legislation, and strictly abiding with national cultural traits, and on the other side the government appears as a source of funding through budget subsidies or guarantees on European programs.

Based on specific statistical and economic indicators, the major task of the research team is to conduct an inquiry among those engaged in cultural industries. The result presupposes the possibility of mapping the cultural industries in Plovdiv. This approach would allow for expanding the knowledge and potential of the cultural industries, appraisal, and for the selection of appropriate business models for administration and financing of art organizations.

Mapping would benefit the local government too - in establishing and implementing policies grounded on scientific proof, which includes the funding of cultural industries nationally or locally. Mapping is also useful for strengthening the relationship of culture and business in promoting contacts, visions, programs and development strategies.

This research is being funded by the Scientific Research Fund of the Ministry of Education and the theme of the project is "Art Management: Plovdiv - Modern Trends and Classical Artistry." By mapping the cultural industries in Plovdiv, their cross section shall be clearly outlined for this city. Applying the market principle, ranging of the cultural industries shall be done. For the mapping and ranging it is not possible to use directly the existing statistical data in the classifiers of businesses without conducting additional research of the registered companies. Therefore, for attaining the research objectives an inquiry shall be used instead.

What is interesting for this research is the progress of economic and market trends in view of assessing the opportunities for utilization of particular investments. The scheduled inquiry shall have a qualitative aspect, too, employing groups of not more than 100 people, in-depth interviews based on a questionnaire.

For conducting the research a systematic approach is selected. The object of the research shall be studied as a whole (the cultural industries of Plovdiv), while composed of separate components. The 
required data shall be recorded directly by the managers of the entities engaged in cultural industries.

The respondents (legal entities represented by their managers) should meet the following three criteria:

First criterion: companies registered in the city of Plovdiv;

Second criterion: doing creative works or being part of the cultural industry;

Third criterion: performing operations relating to or subject to copyright.

The results shall be analyzed and presented before students, professors, politicians and institutions that could utilize this information in their studies, teachings or businesses connected with art and culture.

The methodology for appropriate mapping is characterized with the following specifics:

- Data is comparable, since this indicator allows for more precise and more detailed measuring on the enterprise level in the sphere of cultural industries;

- This methodology takes into account the market principles of development in the cultural industries of Plovdiv;

- This methodology employs standard statistical indicators approved by the National Statistical Institute of Bulgaria and the European Statistic Office "Eurostat" for 2016.

Based on data received from National statistical institute a scoping analysis of the cultural industries registered in Plovdiv was conducted. The total number of companies registered (2016) was 272, they are differentiated by economic activity as shown in Table 1 .

\begin{tabular}{|l|l|c|}
\hline \multicolumn{2}{|c|}{ Table 1: Registered cultural industries in Plovdiv 2016 } \\
\hline $\mathbf{1}$ & \multicolumn{1}{|c|}{ Economic activity } & $\begin{array}{c}\text { Number } \\
\text { of } \\
\text { companies }\end{array}$ \\
\hline $\mathbf{1 .}$ & Manufacturing of musical instruments & 1 \\
\hline $\mathbf{2 .}$ & Preservation and maintaining of cultural and historical heritage & 3 \\
\hline $\mathbf{3 .}$ & Museums & 4 \\
\hline $\mathbf{4 .}$ & Music records and producing & 5 \\
\hline $\mathbf{5 .}$ & Libraries and archives & 6 \\
\hline $\mathbf{6 .}$ & Radio programs and TV programs broadcasting & 7 \\
\hline $\mathbf{7 .}$ & Creative activities in the area of literature and art & 13 \\
\hline $\mathbf{8 .}$ & Photography & 55 \\
\hline $\mathbf{9 .}$ & Performing arts & 57 \\
\hline $\mathbf{1 0 .}$ & Publishing activity & 121 \\
\hline Source: Author & \\
\hline
\end{tabular}

Based on the statistical data a scoping analysis was conducted and a special framework has been developed for segmenting the cultural industries in Plovdiv into several sub-sectors depending on the type of the artistic sphere in it. The following sectors are distinguished:

- Cultural industries in the sector of stage arts (opera, theatre, music, dance) of wide publicity and strong social effect;

- Cultural industries in the sector of contemporary visual arts (video, photography, cinema, design, etc.), exhibitions, installations, etc. forms of presenting contemporary art;

- Cultural industries related to cultural historical heritage;

- Cultural industries, inter-relating art, culture, education and modern technology, inter-cultural dialogue, partnering, mobility and European cultural cooperation (workshops, debates, forums, events);

- Cultural industries relating to cultural press, scientific research, documentary editions, collections, analyses and studies;

- Cultural industries for development of alternative space of culture and alternative art forms.

The Scoping analysis is the first step of the fundamental project research. The next stages include developing questionnaire, inquiring focus groups, analyzing data and mapping of cultural industries in Plovdiv. 
The inquiry shall be held using a questionnaire with the aim of collecting data on the particular organization, address, the sphere of business, proprietorship of the cultural industry, the size, the funding, the turnover, the wages and the number of employees. The empirical research will be conducted in November 2017.

The planned deadline for concluding the research and completing the project is November 2018.

\section{Conclusion}

Cultural and creative industries are a strongly innovative component, possessing significant potential for forming capital and the opening of new jobs through generating and utilizing intellectual property. The development of cultural and creative industries and the setting up of partnering networks in this field is a contemporary and vital objective of the modern social and cultural space. One of the most important perspectives of the regional development is the search for opportunities for realisation of creative potentials and for the establishment of innovative business models which contribute to the cultural projects.

\section{Acknowledgment}

The article is founded by the project DM05/2/2016 „Art management: Plovdiv - new tendencies and classical art (ART), “ Bulgarian Science Fund, Ministry of Education and Science.

\section{References}

Barkalova P. Kazashka C. (2010). Cultural industries - real sector of the economy and necessity. VII Conference Management and Entrepreneurship TU - Plovdiv, pp. 81- 84, Plovdiv, 2010.

Chalakov I. (2006) Creative Industries in the City of Plovdiv - economic vision. British Council - Bulgaria. 2006

National Statistical Institute: Standard statistical indicators list for $2016 \mathrm{http} / / / \mathrm{www} . n s i . b g$

Urban Research, The Laws of The City, Jun 23rd, 2012 